\title{
The Effects of Tamoxifen on Plasma Lipoprotein(a) Concentrations: Systematic Review and Meta-Analysis
}

\author{
Amirhossein Sahebkar $^{1,2} \cdot$ Maria-Corina Serban ${ }^{3,4} \cdot$ Peter Penson $^{5}$. \\ Camelia Gurban $^{6}$ • Sorin Ursoniu ${ }^{7}$ - Peter P. Toth ${ }^{8,9}$ • Steven R. Jones ${ }^{9}$. \\ Giuseppe Lippi ${ }^{10}$ - Kazuhiko Kotani1 ${ }^{11}$ Karam Kostner ${ }^{12}$ - Manfredi Rizzo ${ }^{13}$. \\ Jacek Rysz ${ }^{14,15}$ - Maciej Banach ${ }^{14,15,16,17}$ - for the Lipid and Blood Pressure Meta-analysis \\ Collaboration (LBPMC) Group
}

Published online: 1 June 2017

(C) The Author(s) 2017. This article is an open access publication

\begin{abstract}
Introduction Tamoxifen is a selective estrogen receptor modulator widely used in the treatment of breast cancer. Tamoxifen therapy is associated with lower circulating low-density lipoprotein cholesterol and increased triglycerides, but its effects on other lipids are less well studied. Aims We aimed to investigate the effect of tamoxifen on circulating concentrations of lipoprotein(a) [Lp(a)] through a meta-analysis of available randomized controlled trials (RCTs) and observational studies.

Methods This study was registered in the PROSPERO database (CRD42016036890). Scopus, MEDLINE and
\end{abstract}

Maciej Banach

maciejbanach77@gmail.com

1 Biotechnology Research Center, Mashhad University of Medical Sciences, Mashhad, Iran

2 Metabolic Research Centre, Royal Perth Hospital, School of Medicine and Pharmacology, University of Western Australia, Perth, Australia

3 Department of Epidemiology, University of Alabama at Birmingham, Birmingham, AL, USA

4 Department of Functional Sciences, Discipline of Pathophysiology, "Victor Babes" University of Medicine and Pharmacy, Timisoara, Romania

5 School of Pharmacy and Biomolecular Sciences, Liverpool John Moores University, Liverpool, UK

6 Department of Biochemistry and Pharmacology, Discipline of Biochemistry, "Victor Babes" University of Medicine and Pharmacy, Timisoara, Romania

7 Department of Functional Sciences, Discipline of Public Health, "Victor Babes" University of Medicine and Pharmacy, Timisoara, Romania

8 Preventive Cardiology, CGH Medical Center, Sterling, IL, USA
EMBASE were searched from inception until 22 March 2016 to identify studies investigating the effect of tamoxifen on $\mathrm{Lp}$ (a) values in humans. Meta-analysis was performed using an inverse variance-weighted, random-effects model with standardized mean difference (SMD) as the effect size estimate.

Results Meta-analysis of five studies with 215 participants suggested a statistically significant reduction of $\mathrm{Lp}$ (a) levels following tamoxifen treatment (SMD -0.41 , $95 \%$ confidence interval -0.68 to $-0.14, p=0.003$ ). This effect was robust in the sensitivity analysis.

9 The Johns Hopkins Ciccarone Center for the Prevention of Heart Disease, Baltimore, MD, USA

10 Section of Clinical Biochemistry, University of Verona, Verona, Italy

11 Division of Community and Family Medicine, Jichi Medical University, Shimotsuke, Japan

12 Mater Hospital, University of Queensland, St Lucia, QLD, Australia

13 Biomedical Department of Internal Medicine and Medical Specialties, University of Palermo, Palermo, Italy

14 Chair of Nephrology and Hypertension, Medical University of Lodz, Lodz, Poland

15 Cardiovascular Research Centre, University of Zielona Gora, Zielona Gora, Poland

16 Polish Mother's Memorial Hospital Research Institute, Lodz, Poland

17 Department of Hypertension, WAM University Hospital in Lodz, Medical University of Lodz, Zeromskiego 113, 90-549 Lodz, Poland 
Conclusions Meta-analysis suggested a statistically significant reduction of $\mathrm{Lp}(\mathrm{a})$ levels following tamoxifen treatment. Further well-designed trials are required to validate these results.

\section{Key Points}

Lipoprotein(a) $[\mathrm{Lp}(\mathrm{a})]$ is an emerging risk factor for cardiovascular disease; it is relatively resistant to reduction by dietary and pharmacological methods.

Tamoxifen, a selective estrogen receptor modulator, is widely used in the treatment of breast cancer.

This meta-analysis demonstrates a significant reduction of $L p(a)$ levels after tamoxifen treatment.

\section{Introduction}

Lipoprotein(a) [Lp(a)], first discovered by Kare Berg in 1963, is a low-density lipoprotein (LDL)-like particle containing apolipoprotein(a) [apo(a)] and apolipoprotein B-100 (apo-B100) linked through a disulfide bond [1]. It has been shown that $\mathrm{Lp}$ (a) contributes to atherosclerosis through accelerated transport of oxidized phospholipids [2] and inhibition of fibrinolysis [3]. Plasma Lp(a) levels are influenced by several factors such as genetic polymorphisms of apo(a) [4], sex, age, race [5, 6], smoking, alcohol consumption, dietary habits, intense exercise, thyroid function [7] and hormonal factors. However, Lp(a) appears to be more resistant to drug and lifestyle interventions than any other lipoprotein [8]. A continuous and independent association between enhanced $L p(a)$ levels and risk of coronary heart disease [9], ischemic stroke [10], venous thromboembolism [11], aortic valve stenosis and aortic valve calcification [12] has been observed. Many strategies designed to target $\mathrm{Lp}$ (a) have been tested, including nicotinic acid [13-15], apheresis [16], the apo-B synthesis inhibitor mipomersen [17, 18], inhibitors of proprotein convertase subtilisin/kexin type 9 (PCSK9), coenzyme Q10 [19], cholesteryl ester transfer protein (CETP) inhibitors, aspirin, the thyroid hormone analog eprotirome [20], and synthetic inhibitors of microsomal triglyceride transfer protein [21]. However, the benefit of these strategies in clinical trials seems to be derived from effects on other lipids [22].

Tamoxifen is a selective estrogen receptor modulator (SERM), which has been used since 1977 for the treatment of women with early or advanced stages of breast tumors [23]. SERMS act as agonists of estrogen receptors in some tissues and as antagonists in others [24], hence their designation as "modulators" of estrogen receptors rather than as "agonists" or "antagonists." In addition to its beneficial effects on cancer, it has been suggested that tamoxifen may decrease the risk of cardiovascular disease (CVD) and associated mortality by modulating lipid metabolism [25-27]. In particular, tamoxifen has been associated with a reduction in circulating low-density lipoprotein-cholesterol (LDL-C) [28]. However, tamoxifen was not shown to have any benefit on cardiovascular risk in the Breast Cancer Prevention trial [29]. Moreover, the Heart and Estrogen/ Progestin Replacement Study (HERS) showed that treatment with estrogen plus progestin led to greater CVD risk than placebo in a randomized controlled trial (RCT) in high-risk patients [30]. It is thus important that the effects of individual SERMS and estrogen receptor ligands on lipid profiles and cardiovascular risk are thoughtfully explored, rather than assuming a class effect for these drugs [29].

Some experimental and clinical trials have reported an important role of tamoxifen in decreasing lipids and $\mathrm{Lp}$ (a) levels; however, the available evidence is controversial and mostly inconclusive. Therefore, we aimed to assess the impact of tamoxifen on plasma $L p(a)$ concentrations through a meta-analysis of available RCTs and observational studies.

\section{Methods}

This study was designed according to the guidelines of the 2009 Preferred Reporting Items for Systematic Reviews and Meta-Analysis (PRISMA) statement [31] and was registered in the Prospero database (CRD42016036890).

\subsection{Search Strategy}

Scopus (http://www.scopus.com), EMBASE (http:// www.embase.com) and MEDLINE (http://www.ncbi. nlm.nih.gov/pubmed) databases were searched using the following search terms in titles and abstracts: ("lp(a)" OR "LP (a)" OR "lipoprotein(a)" OR "lipoprotein (a)") AND (tamoxifen). The wild-card term "*” was used to increase the sensitivity of the search strategy. No language restriction was used in the literature search. The search was limited to studies in humans. The literature was searched from inception until 22 March 2016. Two reviewers (MCS and PP) evaluated each article independently. Disagreements were resolved by discussion with a third party (MB). 


\subsection{Study Selection}

Original studies were included if they met the following inclusion criteria: (1) interventional studies (either with a parallel or cross-over design), post hoc analyses and observational studies (either with a prospective or retrospective design); (2) inclusion of a control group; (3) investigating the impact of tamoxifen on plasma/serum concentrations of $\mathrm{Lp}(\mathrm{a})$; and (4) presentation of sufficient information on $\mathrm{Lp}$ (a) concentrations at baseline and at the end of follow-up in each group or providing the net change values. Exclusion criteria were (1) lack of an appropriate control group in the study design and (2) lack of sufficient information on baseline or follow-up $\mathrm{Lp}$ (a) concentrations.

\subsection{Data Extraction}

Eligible studies were reviewed, and the following data were abstracted: (1) first author's name; (2) year of publication; (3) study location; (4) study design; (5) inclusion criteria and underlying disease; (6) number of participants in the statin and control (in case of randomized design) groups; (7) age, gender and body mass index (BMI) of study participants; and (8) baseline, follow-up and change values of plasma $L p(a)$ concentrations. Data extraction was performed independently by two reviewers; disagreements were resolved by a third reviewer. Risk of bias in nonrandomized and observational studies was assessed using the Risk Of Bias In Non-randomized Studies of Interventions (ROBINS-I) tool [32]. This tool evaluates the risk of bias across seven domains, including confounding, selection of participants, classification of interventions, deviation from intended interventions, missing data, measurement of outcomes or interventions, and selection of reported results.

\subsection{Quality Assessment}

A systematic assessment of bias in the included studies was performed using the Cochrane criteria [33]. The items used for the assessment of each study were as follows: adequacy of sequence generation, allocation concealment, blinding, dropouts addressed (incomplete outcome data), selective outcome reporting, and other potential sources of bias. According to the recommendations of the Cochrane handbook, a judgment of "yes" indicated low risk of bias, while "no" indicated high risk of bias. Labeling an item as "unclear" indicated an unclear or unknown risk of bias. Risk-ofbias assessment was performed independently by two reviewers; disagreements were resolved by a third reviewer.

\subsection{Quantitative Data Synthesis}

Meta-analysis was conducted using Comprehensive MetaAnalysis (CMA) V2 software (Biostat, NJ) [34]. Net changes in measurements (change scores) were calculated as follows: measure at end of follow-up - measure at baseline. For cross-over trials, net change in plasma concentrations of $\mathrm{Lp}(\mathrm{a})$ were calculated by subtracting the value after the control intervention from that reported after treatment. All values were collated in $\mathrm{mg} / \mathrm{dL}$. Standard deviations (SDs) of the mean difference were calculated using the following formula: $\mathrm{SD}=$ square root $\left[\left(\mathrm{SD}_{\text {pre-treatment }}\right)^{2}+\left(\mathrm{SD}_{\text {post-treatment }}\right)^{2}-\left(2 R \times \mathrm{SD}_{\text {pre-treatment }} \times\right.\right.$ $\left.\mathrm{SD}_{\text {post-treatment }}\right)$, assuming a correlation coefficient $(R)=0.5$. If the outcome measures were reported in median and interquartile range, mean and SD values were estimated using the method described by Hozo et al. [35]. To convert interquartile range into minimum-maximum range, the following equations were used: $A=$ median $+2 \times\left(Q_{3}-\right.$ median) and $B=$ median $-2 \times$ (median $-Q_{1}$ ), where $A, B, Q_{1}$ and $Q_{3}$ are upper and lower ends of the range and upper and lower ends of the interquartile range, respectively. Where only standard error of the mean (SEM) was reported, SD was estimated using the following formula: $\mathrm{SD}=\mathrm{SEM} \times$ square $\operatorname{root}(n)$, where $n$ is the number of subjects. When the results were presented in multiple time points, only data relating to the longest duration of treatment were considered. In order to avoid the double-counting problem in trials comparing multiple treatment arms versus a single control group, the number of subjects in the control group was divided by the number of treatment arms. When no SD was provided for plasma Lp(a) concentrations in a study, the pooled SD of other studies was used as the substitute. When the data were not tabulated, but presented only as graphs, the software GetData Graph Digitizer 2.24 (http://getdatagraph-digitizer.com/) was applied to digitize and extract the data.

A random-effects model (using the DerSimonian-Laird method) and the generic inverse variance method were used to compensate for the heterogeneity of studies in terms of demographic characteristics of populations being studied and also differences in study designs. Heterogeneity was quantitatively assessed using the $I^{2}$ index. Effect sizes were expressed as standardized mean difference (SMD) and 95\% confidence interval (CI). In order to evaluate the influence of each study on the overall effect size, sensitivity analysis was conducted using the leaveone-out method, i.e., removing one study each time and repeating the analysis [36-38]. 


\section{Results}

\subsection{Flow and Characteristics of Included Studies}

The initial screening for potential relevance removed the articles whose titles and/or abstracts were obviously irrelevant. Among the 11 full-text articles assessed for eligibility, six studies were excluded because of the following reasons: study was not controlled for tamoxifen $(n=1)$, duplicate data report $(n=3)$, incomplete data $(n=1)$, not measuring Lp(a) $(n=1)$ (Fig. 1). After assessment, five studies met the inclusion criteria and were included in the meta-analysis $[28,39-42]$. In total, 104 participants were allocated to the tamoxifen group and 111 to the control group in the selected studies. The number of participants in these studies ranged from 17 to 68. Included studies were published between 1994 and 2003, and were conducted in USA (two studies), Italy, Turkey and the UK. All studies used tamoxifen tablets, and the administered dosage ranged from $10 \mathrm{mg}$ administered on alternate days to $40 \mathrm{mg} /$ day. The duration of tamoxifen therapy ranged between 56 days and 14 months. Five studies were designed as randomized parallel-group trials and one as an observational study. Demographic and baseline parameters of the included studies are shown in Table 1. The assessment of risk of bias in the included studies using Cochrane criteria is shown in Table 2. Most of the included studies had a low risk of bias with respect to different criteria specified for the quality assessment. However, the studies by Decensi et al. [43] and Love et al. [44] were identified as having a high risk regarding blinding of participants and personnel and outcome assessment.

\subsection{Effect of Tamoxifen on Plasma Lp(a) Concentrations}

The impact of tamoxifen on plasma $\operatorname{Lp}(\mathrm{a})$ concentrations was reported in seven treatment arms. Meta-analysis suggested a significant reduction of $\mathrm{Lp}$ (a) levels following tamoxifen treatment (SMD $-0.41,95 \%$ CI -0.68 to $0.14, p=0.003 ; I^{2}=0 \% ; Q=1.97$ ) (Fig. 2). This result was robust in the sensitivity analysis (Fig. 3). Likewise, when the studies with higher risk of bias were removed from the meta-analysis, the effect size remained statistically significant (SMD $-0.49,95 \%$ CI -0.92 to -0.05 , $\left.p=0.027 ; I^{2}=0 \% ; Q=1.44\right)$.

\section{Discussion}

To our knowledge, this meta-analysis is the first to collate the evidence obtained from RCTs and observational studies on the efficacy of supplementation with tamoxifen on plasma $\mathrm{Lp}$ (a) concentrations. The results suggested a statistically significant reduction of circulating $\mathrm{Lp}$ (a) concentrations following tamoxifen treatment. Based on a general rule of thumb, our estimated effect size could be regarded as a small to medium effect.

Our results are in agreement with the findings of other studies whose design did not make them eligible for inclusion in this study. For example, in a study that included 38 tamoxifen-treated $(20 \mathrm{mg} /$ day $)$ postmenopausal women with breast cancer, Elisaf et al. observed a statistically significant reduction in median circulating concentrations of $\mathrm{Lp}(\mathrm{a})$ [45]. These methods and results were very similar to those of a small study performed by Shewmon et al., where a stable reduction in $\mathrm{Lp}$ (a) was observed after 1 month of tamoxifen therapy in five out of six study participants with breast cancer [46].

Similar effects have been observed with other SERMS. In a recent systematic review and meta-analysis of 12 studies with 1009 patients, tibolone was shown to be effective in decreasing $\mathrm{Lp}$ (a) levels in postmenopausal women [47]. Tibolone has estrogenic, progestogenic, and weak androgenic actions, and together, the results of these two meta-analysis suggest that further investigation of estrogen receptor ligands may be fruitful in the treatment of elevated $\mathrm{Lp}(\mathrm{a})$.

The effects of tamoxifen on lipid metabolism have been researched in several experimental and clinical studies, but the exact mechanisms responsible for tamoxifen-lowering effects on $\mathrm{Lp}$ (a) levels are not fully understood. Because tamoxifen acts as an agonist of estrogen receptors in some tissues [48, 49], we can look to the effects of estrogen on the liver and on lipoprotein metabolism to help us understand the effects of tamoxifen. Barton has extensively reviewed the effects of estrogen on cholesterol and atherosclerosis [50]. With respect to $\operatorname{Lp}(\mathrm{a})$, it has been demonstrated that hormone replacement therapy (HRT) with estrogen leads to lower circulating $\mathrm{Lp}$ (a) concentrations [51] and that letrozole, an aromatase inhibitor that reduces endogenous production of estrogen, has the opposite effect on $\mathrm{Lp}$ (a) [52]. Estrogen may mediate its effects by altering the biosynthesis of $L p(a)$ and thus reducing the availability of precursors and component molecules, in particular apoB-100 and apo(a). Circulating concentrations of $\mathrm{Lp}(\mathrm{a})$ levels are determined to a greater extent by genetically defined hepatic biosynthesis than by catabolism [53]; estrogens are known to enhance hepatic very low-density lipoprotein (VLDL) synthesis and excretion [4], thus leaving less apoB-100 available for the biosynthesis of $\mathrm{Lp}$ (a). Apo(a) has an interleukin-6 (IL-6) responsive element in its gene promoter region [54], and estrogens may regulate apo(a) levels indirectly through their impact on IL-6 [55], despite the fact that tamoxifen 
Fig. 1 Flow chart of the number of studies identified and included into the meta-analysis

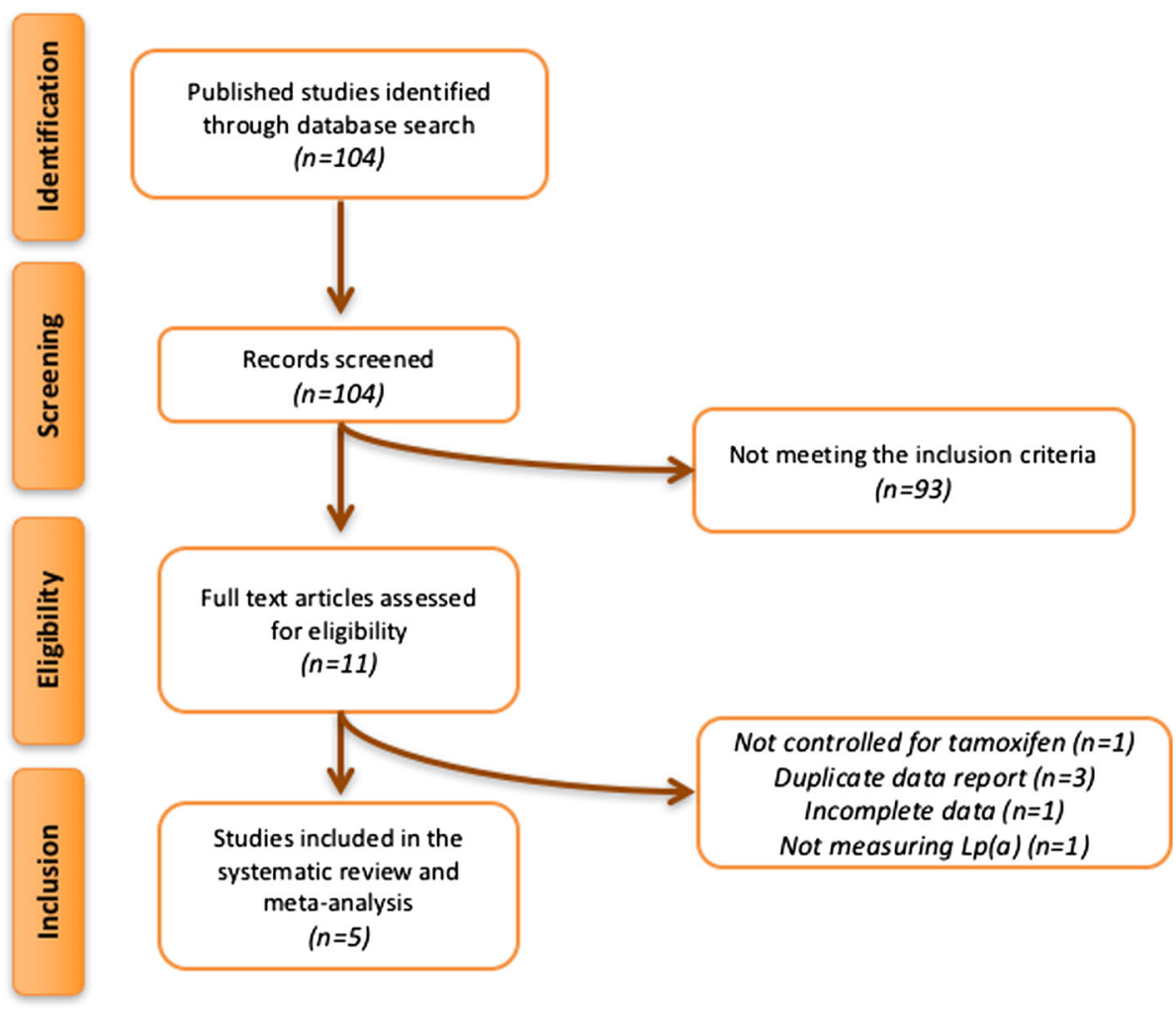

was found to be associated with increased apo(a) in one clinical study [28].

Recent in vitro studies have shed light on potential mechanisms by which the effect of tamoxifen may be mediated. Experiments employing primary hepatocytes [56] and HepG2 hepatocytes [57] supported evidence for a role of LDL receptors (LDLRs) in the catabolism of Lp(a). In the same cell type, the SERMS tamoxifen, raloxifene and toremifene have been shown to up-regulate LDLR activity [58]. Similar effects of estradiol have been observed in the rat, leading to up-regulation of hepatic LDLR and a reduction of LDL [59]. It is not clear whether the same effects would occur in humans in vivo at clinically relevant doses of SERMS; however, these experimental results highlight plausible mechanisms by which tamoxifen may reduce circulating concentrations of Lp(a).

Although tamoxifen has a generally favorable safety profile, long-term use of tamoxifen is associated with serious side effects, including menopause symptoms, endometrial cancer, and thromboembolism, which have all led to controversy regarding its use [60]. Of particular concern with respect to lipid profiles, tamoxifen has been shown to increase circulating concentrations of triglycerides [61, 62], which can cause life-threatening acute pancreatitis [63, 64]. These limitations in the overall risk:benefit ratio of tamoxifen, in addition to the potential development of drug resistance and problems associated with patient compliance, have led to the development of better tolerated and more effective endocrine agents.

The adverse effects described above are likely to limit the usefulness of tamoxifen as a clinical modulator of Lp(a). Nevertheless, the results of this meta-analysis are important because tamoxifen has been shown to reduce plasma concentrations of $L p(a)$, despite the fact that this lipoprotein is relatively resistant to treatment with other drugs and diet [8]. Furthermore, Lp(a) may partially account for residual cardiovascular risk after optimal LDL reduction with statins $[65,66]$. Thus, $\mathrm{Lp}$ (a) should be regarded as a crucial clinical target, and the results of the present study suggest that estrogen receptor ligands show promise in this respect. Finally, the widespread use of tamoxifen and especially its use in the prophylaxis of breast cancer [67] makes it important that clinicians understand the cardiovascular effects of such treatment. The present study adds to our understanding of this issue.

The present meta-analysis has some limitations. There were only a few eligible RCTs, and most of them had a modest number of participants. Administered tamoxifen dose in the included studies was mainly fixed at $20 \mathrm{mg} / \mathrm{day}$, and this hindered assessment of any dose-response association for the $\mathrm{Lp}(\mathrm{a})$-lowering activity of the drug. Furthermore, the included studies were heterogeneous concerning the characteristics of patients, study design, duration and the methods of $L p(a)$ quantification. Finally, it remains somewhat unclear whether the calculated $\mathrm{Lp}(\mathrm{a})$ - 


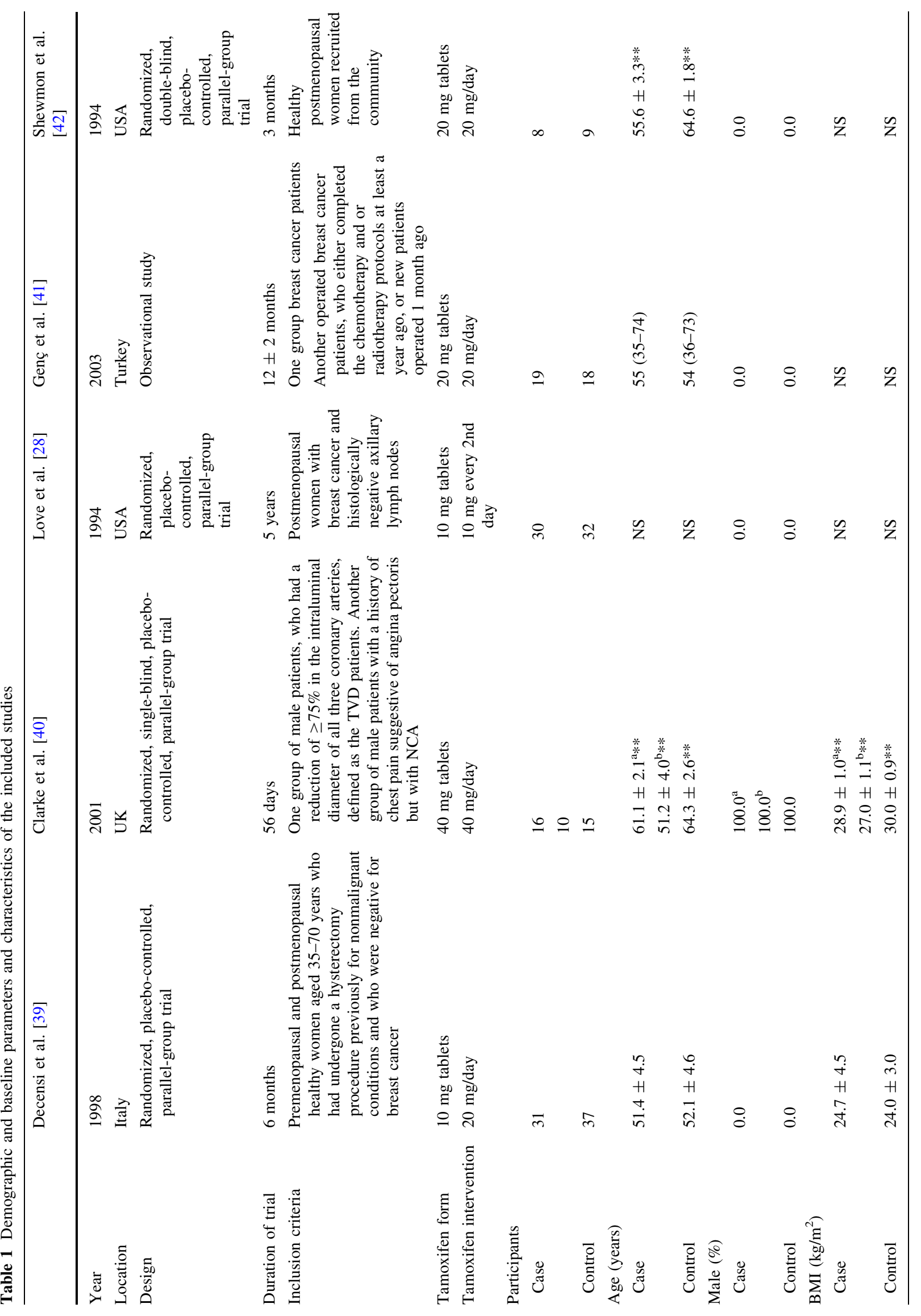




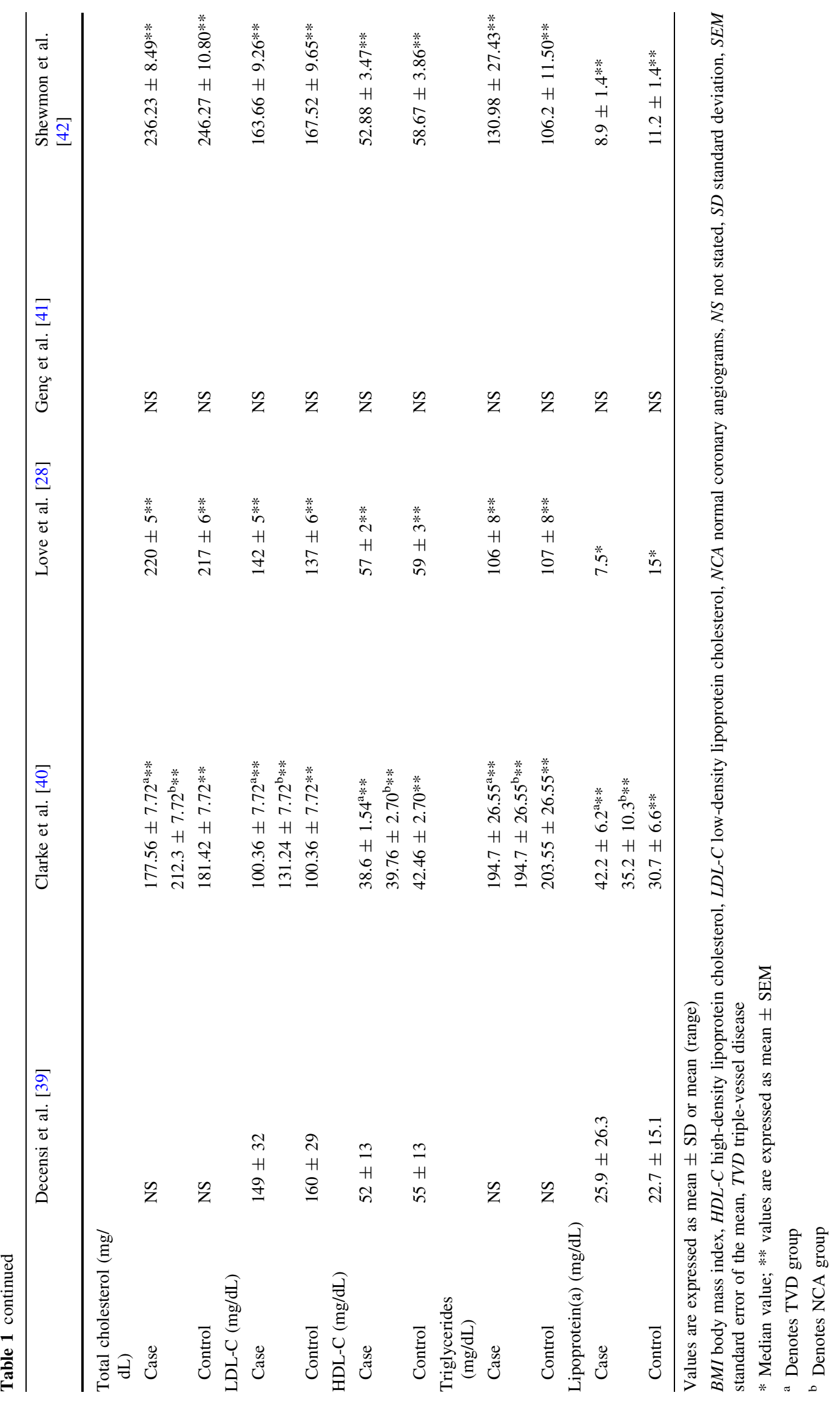


Table 2 Assessment of risk of bias in the included studies using Cochrane criteria

\begin{tabular}{|c|c|c|c|c|c|c|c|}
\hline Study & $\begin{array}{l}\text { Sequence } \\
\text { generation }\end{array}$ & $\begin{array}{l}\text { Allocation } \\
\text { concealment }\end{array}$ & $\begin{array}{l}\text { Blinding of } \\
\text { participants and } \\
\text { personnel }\end{array}$ & $\begin{array}{l}\text { Blinding of outcome } \\
\text { assessment }\end{array}$ & $\begin{array}{l}\text { Incomplete } \\
\text { outcome } \\
\text { data }\end{array}$ & $\begin{array}{l}\text { Selective } \\
\text { outcome } \\
\text { reporting }\end{array}$ & $\begin{array}{l}\text { Other potential } \\
\text { threats to validity }\end{array}$ \\
\hline $\begin{array}{l}\text { Decensi } \\
\text { et al. } 1998 \\
\text { [39] }\end{array}$ & $\mathrm{U}$ & $\mathrm{U}$ & $\mathrm{H}$ & $\mathrm{H}$ & $\mathrm{L}$ & $\mathrm{L}$ & $\mathrm{L}$ \\
\hline $\begin{array}{l}\text { Clarke et al. } \\
2001[40]\end{array}$ & $\mathrm{L}$ & $\mathrm{L}$ & $\mathrm{L}$ & $\mathrm{L}$ & $\mathrm{L}$ & $\mathrm{L}$ & $\mathrm{L}$ \\
\hline $\begin{array}{l}\text { Love et al. } \\
1994 \text { [28] }\end{array}$ & $\mathrm{L}$ & $\mathrm{L}$ & $\mathrm{H}$ & $\mathrm{H}$ & $\mathrm{L}$ & $\mathrm{L}$ & $\mathrm{L}$ \\
\hline Shewmon & $\mathrm{U}$ & $\mathrm{U}$ & $\mathrm{L}$ & $\mathrm{L}$ & $\mathrm{L}$ & $\mathrm{L}$ & $\mathrm{L}$ \\
\hline $\begin{array}{l}\text { et al. } 1994 \\
\text { [42] }\end{array}$ & $\begin{array}{l}\text { Bias due to } \\
\text { confounding }\end{array}$ & $\begin{array}{l}\text { Bias in } \\
\text { participant } \\
\text { selection }\end{array}$ & $\begin{array}{l}\text { Bias in } \\
\text { classification of } \\
\text { interventions }\end{array}$ & $\begin{array}{l}\text { Bias due to departures } \\
\text { from intended } \\
\text { interventions }\end{array}$ & $\begin{array}{l}\text { Bias due to } \\
\text { missing } \\
\text { data }\end{array}$ & $\begin{array}{l}\text { Bias in } \\
\text { measurement } \\
\text { of outcomes }\end{array}$ & $\begin{array}{l}\text { Bias in selection } \\
\text { of the reported } \\
\text { result }\end{array}$ \\
\hline $\begin{array}{l}\text { Genç et al. } \\
2003 \\
{[41]^{\mathrm{a}}}\end{array}$ & $\mathrm{L}$ & $\mathrm{L}$ & $\mathrm{L}$ & $\mathrm{L}$ & $\mathrm{L}$ & $\mathrm{L}$ & $\mathrm{L}$ \\
\hline
\end{tabular}

Risk of bias assessment according to the Cochrane Collaboration's tool for randomized controlled trials and ROBINS-I tool for non-randomized and observational studies

$H$ high risk of bias, $L$ low risk of bias, ROBINS-I Risk Of Bias In Non-randomized Studies of Interventions, $U$ unclear risk of bias

a Study had an observational design

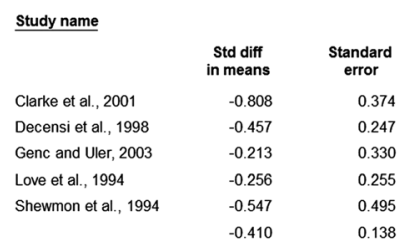

\begin{tabular}{rcc}
\multicolumn{2}{c}{ Statistics for each study } & \\
Variance & $\begin{array}{c}\text { Lower } \\
\text { limit }\end{array}$ & $\begin{array}{c}\text { Upper } \\
\text { limit }\end{array}$ \\
0.140 & -1.541 & -0.076 \\
0.061 & -0.941 & 0.026 \\
0.109 & -0.860 & 0.433 \\
0.065 & -0.756 & 0.244 \\
0.245 & -1.517 & 0.423 \\
0.019 & -0.681 & -0.139
\end{tabular}
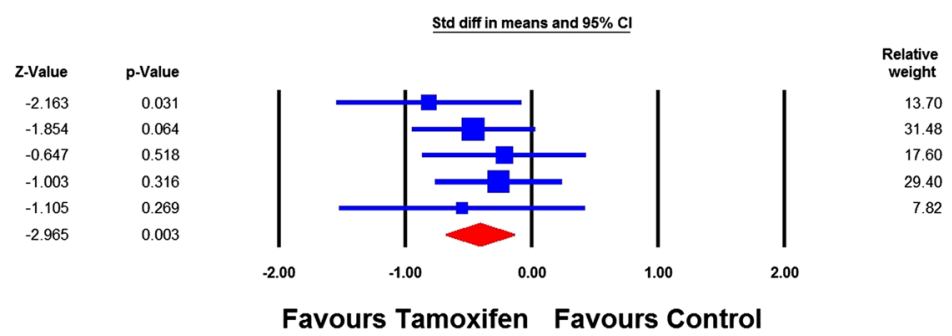

Fig. 2 Forest plot detailing standardized mean difference and 95\% confidence intervals (CIs) for the impact of tamoxifen on plasma lipoprotein(a) concentrations $\left(I^{2}=0 \% ; Q=1.97, p=0.741\right)$

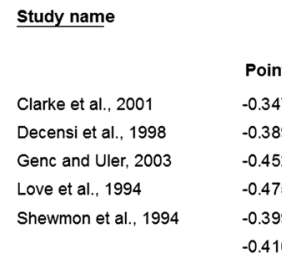

\begin{tabular}{ccc}
\multicolumn{3}{c}{ Statistics with study removed } \\
Variance & $\begin{array}{c}\text { Lower } \\
\text { limit }\end{array}$ & $\begin{array}{c}\text { Upper } \\
\text { limit }\end{array}$ \\
0.022 & -0.639 & -0.055 \\
0.028 & -0.716 & -0.061 \\
0.023 & -0.751 & -0.154 \\
0.027 & -0.797 & -0.152 \\
0.021 & -0.681 & -0.116 \\
0.019 & -0.681 & -0.139
\end{tabular}

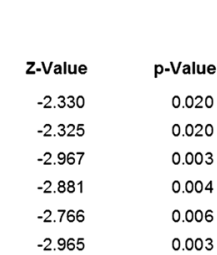

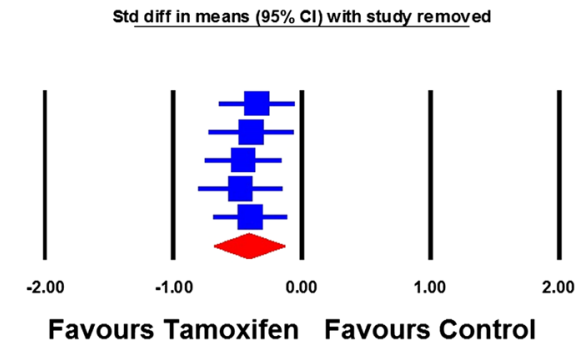

Fig. 3 Leave-one-out sensitivity analysis of the meta-analysis of tamoxifen's effects on plasma lipoprotein(a) concentrations. Sensitivity analysis was performed by iterative removal of each study and repeating the analysis. $C I$ confidence interval

lowering effect of tamoxifen can be translated to a clinically relevant cardiovascular risk reduction. Addressing this uncertainty necessitates additional evidence from large-scale trials, particularly those performed in subjects with elevated plasma $\mathrm{Lp}$ (a) concentrations at baseline.

\section{Conclusion}

This meta-analysis suggests a statistically significant reduction of $\mathrm{Lp}(\mathrm{a})$ levels after tamoxifen treatment. Further well-designed trials are required to validate these results. 
Author contributions Maciej Banach, Maria-Corina Serban, Camelia Gurban, Sorin Ursoniu and Amirhossein Sahebkar conceived and designed the work, and contributed to the drafting of the manuscript. Maria-Corina Serban, Peter Penson and Sorin Ursoniu performed the searches and extracted data. Amirhossein Sahebkar performed the statistical analysis. Peter Penson, Peter P. Toth, Steven R. Jones, Giuseppe Lippi, Kazuhiko Kotani, Karam Kostner, Manfredi Rizzo, Jacek Rysz and Maciej Banach contributed to the interpretation of the work and revised the manuscript critically for important intellectual content. All authors have approved the final manuscript and agree to be held accountable for all aspects of the work.

\section{Compliance with ethical standards}

Conflicts of interest This meta-analysis was written independently; no company or institution supported it financially. Dr. Penson owns four shares in AstraZeneca PLC, which he inherited during 2015. Dr. Toth is a member of the speakers' bureau for Amarin, Amgen, Merck, and Regeneron-Sanofi; and a consultant to Amarin, Amgen, AstraZeneca, Kowa, Merck, and Regeneron-Sanofi. No professional writer was involved in the preparation of this meta-analysis.

Open Access This article is distributed under the terms of the Creative Commons Attribution-NonCommercial 4.0 International License (http://creativecommons.org/licenses/by-nc/4.0/), which permits any noncommercial use, distribution, and reproduction in any medium, provided you give appropriate credit to the original author(s) and the source, provide a link to the Creative Commons license, and indicate if changes were made.

\section{References}

1. Bermudez V, Arráiz N, Aparicio D, Rojas E, Gotera D, Guerra X, et al. Lipoprotein (a): from molecules to therapeutics. Am J Ther. 2010;17(3):263-73.

2. Banach M. Lipoprotein (a)-We Know So Much Yet Still Have Much to Learn .... J Am Heart Assoc. 2016;5(4):e003597.

3. Hancock MA, Boffa MB, Marcovina SM, Nesheim ME, Koschinsky ML. Inhibition of plasminogen activation by lipoprotein (a) critical domains in apolipoprotein (a) and mechanism of inhibition on fibrin and degraded fibrin surfaces. J Biol Chem. 2003;278(26):23260-9.

4. Rader DJ, Cain W, Ikewaki K, Talley G, Zech L, Usher D, et al. The inverse association of plasma lipoprotein (a) concentrations with apolipoprotein (a) isoform size is not due to differences in Lp (a) catabolism but to differences in production rate. J Clin Investig. 1994;93(6):2758.

5. Kotani K, Serban MC, Penson P, Lippi G, Banach M. Evidencebased assessment of lipoprotein(a) as a risk biomarker for cardiovascular diseases - Some answers and still many questions. Crit Rev Clin Lab Sci. 2016;53(6):370-8.

6. Guan W, Cao J, Steffen BT, Post WS, Stein JH, Tattersall MC, et al. Race is a key variable in assigning lipoprotein (a) cutoff values for coronary heart disease risk assessment the multi-ethnic study of atherosclerosis. Arterioscler Thromb Vasc Biol. 2015;35(4):996-1001.

7. Lippi G, Targher G, Montagnana M, Salvagno GL, Guidi GC. Relationship between lipoprotein (a) and thyroid function status in the general population. Arch Med Res. 2007;38(8):905-6.

8. Bos S, Yayha R, van Lennep JE. Latest developments in the treatment of lipoprotein (a). Curr Opin Lipidol. 2014;25(6):452-60.
9. Emerging Risk Factors Collaboration. Lipoprotein (a) concentration and the risk of coronary heart disease, stroke, and nonvascular mortality. JAMA. 2009;302(4):412.

10. Ohira T, Schreiner PJ, Morrisett JD, Chambless LE, Rosamond WD, Folsom AR. Lipoprotein (a) and incident ischemic stroke the Atherosclerosis Risk in Communities (ARIC) Study. Stroke. 2006;37(6):1407-12.

11. von Depka M, Nowak-Göttl U, Eisert R, Dieterich C, Barthels M, Scharrer I, et al. Increased lipoprotein (a) levels as an independent risk factor for venous thromboembolism. Blood. 2000;96(10):3364-8.

12. Vongpromek R, Bos S, Kate GJ, Yahya R, Verhoeven A, Feyter $\mathrm{P}$, et al. Lipoprotein (a) levels are associated with aortic valve calcification in asymptomatic patients with familial hypercholesterolaemia. J Intern Med. 2015;278(2):166-73. doi: 10. 1111/joim. 12335 .

13. Nordestgaard BG, Chapman MJ, Ray K, Borén J, Andreotti F, Watts GF, et al. Lipoprotein (a) as a cardiovascular risk factor: current status. Eur Heart J. 2010;31(23):2844-53.

14. Goldstein LB, Bushnell CD, Adams RJ, Appel LJ, Braun LT, Chaturvedi $S$, et al. Guidelines for the primary prevention of stroke a guideline for healthcare professionals from the American Heart Association/American Stroke Association. Stroke. 2011;42(2):517-84.

15. Sahebkar A, Reiner Z, Simental-Mendia LE, Ferretti G, Cicero AF. Effect of extended-release niacin on plasma lipoprotein(a) levels: a systematic review and meta-analysis of randomized placebo-controlled trials. Metab Clin Exp. 2016;65(11):1664-78.

16. Marcovina SM, Koschinsky ML, Albers JJ, Skarlatos S. Report of the National Heart, Lung, and Blood Institute workshop on lipoprotein (a) and cardiovascular disease: recent advances and future directions. Clin Chem. 2003;49(11):1785-96.

17. Gouni-Berthold I, Berthold HI. Lipoprotein (a): current perspectives. Curr Vasc Pharmacol. 2011;9(6):682-92.

18. Sahebkar A, Watts GF. New therapies targeting apoB metabolism for high-risk patients with inherited dyslipidaemias: what can the clinician expect? Cardiovasc Drugs Ther. 2013;27(6):559-67.

19. Sahebkar A, Simental-Mendia LE, Stefanutti C, Pirro M. Supplementation with coenzyme Q10 reduces plasma lipoprotein(a) concentrations but not other lipid indices: a systematic review and meta-analysis. Pharmacol Res. 2016;105:198-209.

20. Ladenson PW, Kristensen JD, Ridgway EC, Olsson AG, Carlsson $\mathrm{B}$, Klein I, et al. Use of the thyroid hormone analogue eprotirome in statin-treated dyslipidemia. $\mathrm{N}$ Engl $\mathrm{J}$ Med. 2010;362(10):906-16.

21. Banach M, Aronow WS, Serban C, Sahabkar A, Rysz J, Voroneanu L, et al. Lipids, blood pressure and kidney update 2014. Pharmacol Res. 2015;95:111-25.

22. Man LC, Kelly E, Duffy D. Targeting lipoprotein (a): an evolving therapeutic landscape. Curr Atheroscler Rep. 2015;17(5):1-10.

23. Lim Y-P, Lin C-L, Lin Y-N, Ma W-C, Hung D-Z, Kao C-H. Tamoxifen treatment and the reduced risk of hyperlipidemia in Asian patients with breast cancer: a population-based cohort study. Clin Breast Cancer. 2015;15(4):294-300. doi:10.1016/j. clbc.2015.03.005.

24. Jordan VC. SERMs: meeting the promise of multifunctional medicines. J Natl Cancer Inst. 2007;99(5):350-6.

25. Imperato F, Marziani R, Perniola G, Ebano V, Fruscella M, Mossa B. Effects of tamoxifen and estrogen replacement therapy on lipid metabolism and some other cardiovascular risk factors. A prospective study in hysterectomised women. Minerva Ginecol. 2003;55(1):87-93.

26. Nordenskjöld B, Rosell J, Rutqvist L-E, Malmström P-O, Bergh $\mathrm{J}$, Bengtsson $\mathrm{N}-\mathrm{O}$, et al. Coronary heart disease mortality after 
5 years of adjuvant tamoxifen therapy: results from a randomized trial. J Natl Cancer Inst. 2005;97(21):1609-10.

27. Henderson VW, Lobo RA. Hormone therapy and the risk of stroke: perspectives 10 years after the Women's Health Initiative trials. Climacteric. 2012;15(3):229-34.

28. Love RR, Wiebe DA, Feyzi JM, Newcomb PA, Chappell RJ. Effects of tamoxifen on cardiovascular risk factors in postmenopausal women after 5 years of treatment. J Natl Cancer Inst. 1994;86(20):1534-9.

29. Reis SE, Costantino JP, Wickerham DL, Tan-Chiu E, Wang J, Kavanah M. Cardiovascular effects of tamoxifen in women with and without heart disease: breast cancer prevention trial. J Natl Cancer Inst. 2001;93(1):16-21.

30. Hulley S, Grady D, Bush T, Furberg C, Herrington D, Riggs B, et al. Randomized trial of estrogen plus progestin for secondary prevention of coronary heart disease in postmenopausal women. Heart and Estrogen/progestin Replacement Study (HERS) Research Group. JAMA. 1998;280(7):605-13.

31. Moher D, Liberati A, Tetzlaff J, Altman DG, Group P. Preferred reporting items for systematic reviews and meta-analyses: the PRISMA statement. Int J Surg. 2010;8(5):336-41.

32. Sterne JA, Hernan MA, Reeves BC, Savovic J, Berkman ND, Viswanathan M, et al. ROBINS-I: a tool for assessing risk of bias in non-randomised studies of interventions. BMJ. 2016;12(355):i4919.

33. Higgins J, Green S. The Cochrane handbook for systematic reviews of interventions, version 5.0. 2. London: The Cochrane Collaboration. http://www.cochrane-handbook.org; 2009.

34. Borenstein M, Higgins JP. Meta-analysis and subgroups. Prev Sci. 2013;14(2):134-43.

35. Hozo SP, Djulbegovic B, Hozo I. Estimating the mean and variance from the median, range, and the size of a sample. BMC Med Res Methodol. 2005;5(1):1-10.

36. Sahebkar A. Does PPAR $\gamma 2$ gene Pro12Ala polymorphism affect nonalcoholic fatty liver disease risk? Evidence from a metaanalysis. DNA Cell Biol. 2013;32(4):188-98.

37. Sahebkar A. Are curcuminoids effective C-reactive protein-lowering agents in clinical practice? Evidence from a meta-analysis. Phytother Res. 2014;28(5):633-42.

38. Ferretti G, Bacchetti T, Sahebkar A. Effect of statin therapy on paraoxonase-1 status: a systematic review and meta-analysis of 25 clinical trials. Prog Lipid Res. 2015;60:50-73.

39. Decensi A, Bonanni B, Guerrieri-Gonzaga A, Gandini S, Robertson C, Johansson $\mathrm{H}$, et al. Biologic activity of tamoxifen at low doses in healthy women. $\mathbf{J}$ Natl Cancer Inst. 1998;90(19):1461-7.

40. Clarke SC, Schofield PM, Grace AA, Metcalfe JC, Kirschenlohr HL. Tamoxifen effects on endothelial function and cardiovascular risk factors in men with advanced atherosclerosis. Circulation. 2001;103(11):1497-502.

41. Genç S, Tanrıkulu-Kılıç F, Gürdöl F, Ünlüçerçi Y, Üler P, Lama A, et al. Effect of tamoxifen on fibrinogen, D-dimer, lipid and lipoprotein concentrations in breast cancer patients. Clin Chim Acta. 2003;337(1):177-9.

42. Shewmon DA, Stock JL, Rosen CJ, Heiniluoma KM, Hogue MM, Morrison A, et al. Tamoxifen and estrogen lower circulating lipoprotein (a) concentrations in healthy postmenopausal women. Arterioscler Thromb Vasc Biol. 1994;14(10):1586-93.

43. Decensi A, Bonanni B, Guerrieri-Gonzaga A, Gandini S, Robertson C, Johansson H, et al. Biologic activity of tamoxifen at low doses in healthy women. J Natl Cancer Inst. 1998;90(19):1461-7.

44. Love RR, Wiebe DA, Feyzi JM, Newcomb PA, Chappell RJ. Effects of tamoxifen on cardiovascular risk factors in postmenopausal women after 5 years of treatment. J Natl Cancer Inst. 1994;86(20):1534-9.
45. Elisaf M, Bairaktari E, Nicolaides C, Fountzilas G, Tzallas C, Siamopoulos K, et al. The beneficial effect of tamoxifen on serum lipoprotein-A levels: an additional anti-atherogenic property. Anticancer Res. 1996;16(5A):2725-8.

46. Shewmon DA, Stock JL, Abusamra LC, Kristan MA, Baker S, Heiniluoma KM. Tamoxifen decreases lipoprotein (a) in patients with breast cancer. Metabolism. 1994;43(5):531-2.

47. Kotani K, Sahebkar A, Serban C, Andrica F, Toth PP, Jones SR, et al. Tibolone decreases Lipoprotein(a) levels in postmenopausal women: a systematic review and meta-analysis of 12 studies with 1009 patients. Atherosclerosis. 2015;242(1):87-96.

48. Musa MA, Khan MO, Cooperwood JS. Medicinal chemistry and emerging strategies applied to the development of selective estrogen receptor modulators (SERMs). Curr Med Chem. 2007;14(11):1249-61.

49. Lewis S. Do endocrine treatments for breast cancer have a negative impact on lipid profiles and cardiovascular risk in postmenopausal women? Am Heart J. 2007;153(2):182-8.

50. Barton M. Cholesterol and atherosclerosis: modulation by oestrogen. Curr Opin Lipidol. 2013;24(3):214-20.

51. Howard BV, Rossouw JE. Estrogens and cardiovascular disease risk revisited: the Women's Health Initiative. Curr Opin Lipidol. 2013;24(6):493-9.

52. Wasan KM, Goss PE, Pritchard PH, Shepherd L, Tu D, Ingle JN. Lipid concentrations in postmenopausal women on letrozole after 5 years of tamoxifen: an NCIC CTG MA.17 sub-study. Breast Cancer Res Treat. 2012;136(3):769-76.

53. Hofmann SL, Eaton DL, Brown MS, McConathy WJ, Goldstein JL, Hammer RE. Overexpression of human low density lipoprotein receptors leads to accelerated catabolism of $\mathrm{Lp}$ (a) lipoprotein in transgenic mice. $\mathbf{J}$ Clin Invest. 1990;85(5):1542-7.

54. Lawn RM. The apolipoprotein(a) gene: characterization of $5^{\prime}$ flanking regions and expression in transgenic mice. Chem Phys Lipids. 1994;67-68:19-23.

55. Jilka RL, Hangoc G, Girasole G, Passeri G, Williams DC, Abrams JS, et al. Increased osteoclast development after estrogen loss: mediation by interleukin-6. Science. 1992;257(5066):88-91.

56. Snyder ML, Hay RV, Whitington PF, Scanu AM, Fless GM. Binding and degradation of lipoprotein(a) and LDL by primary cultures of human hepatocytes. Comparison with cultured human monocyte-macrophages and fibroblasts. Arterioscler Thromb. 1994;14(5):770-9.

57. Romagnuolo R, Scipione CA, Boffa MB, Marcovina SM, Seidah NG, Koschinsky ML. Lipoprotein(a) catabolism is regulated by proprotein convertase subtilisin/kexin type 9 through the low density lipoprotein receptor. J Biol Chem. 2015;290(18): 11649-62.

58. Cerrato F, Fernandez-Suarez ME, Alonso R, Alonso M, Vazquez $\mathrm{C}$, Pastor $\mathrm{O}$, et al. Clinically used selective oestrogen receptor modulators increase LDL receptor activity in primary human lymphocytes. Br J Pharmacol. 2015;172(5):1379-94.

59. Windler EE, Kovanen PT, Chao YS, Brown MS, Havel RJ, Goldstein JL. The estradiol-stimulated lipoprotein receptor of rat liver. A binding site that membrane mediates the uptake of rat lipoproteins containing apoproteins B and E. J Biol Chem. 1980;255(21):10464-71.

60. Love RR. Tamoxifen therapy in primary breast cancer: biology, efficacy, and side effects. J Clin Oncol. 1989;7(6):803-15.

61. Hozumi Y, Kawano M, Saito T, Miyata M. Effect of tamoxifen on serum lipid metabolism. J Clin Endocrinol Metab. 1998;83(5):1633-5.

62. Liu CL, Yang TL. Sequential changes in serum triglyceride levels during adjuvant tamoxifen therapy in breast cancer patients and the effect of dose reduction. Breast Cancer Res Treat. 2003;79(1):11-6. 
63. Mikhailidis D, Ganotakis E, Georgoulias V, Vallance D, Winder A. Tamoxifen-induced hypertriglyceridaemia. Oncol Rep. 1997;4(3):625-8.

64. Singh HK, Prasad MS, Kandasamy AK, Dharanipragada K. Tamoxifen-induced hypertriglyceridemia causing acute pancreatitis. J Pharmacol Pharmacother. 2016;7(1):38-40.

65. Seed M, Hoppichler F, Reaveley D, McCarthy S, Thompson GR, Boerwinkle E, et al. Relation of serum lipoprotein(a) concentration and apolipoprotein(a) phenotype to coronary heart disease in patients with familial hypercholesterolemia. N Engl J Med. 1990;322(21):1494-9.
66. Jansen AC, van Aalst-Cohen ES, Tanck MW, Trip MD, Lansberg $\mathrm{PJ}$, Liem AH, et al. The contribution of classical risk factors to cardiovascular disease in familial hypercholesterolaemia: data in 2400 patients. J Intern Med. 2004;256(6):482-90.

67. Cuzick J, Sestak I, Cawthorn S, Hamed H, Holli K, Howell A, et al. Tamoxifen for prevention of breast cancer: extended longterm follow-up of the IBIS-I breast cancer prevention trial. Lancet Oncol. 2015;16(1):67-75. 